Background Coimbra is certainly among the Portuguese university cities with more nightlife-oriented towards students. The CPTTP and IREFREA-Portugal, are investing, in partnership with other organisations of our city (Health, Education, Security Forces, Municipality, Others sectors) in primary, secondary, and tertiary prevention in nightlife settings. This initiative aims to contribute: to identify and eliminate the risk factors associated with (potentially) traumatic situations (intentional and unintentional); to identify and enhance protective factors; to strengthen community resilience.

Description of the problem Recreation nightlife plays an important role in students' lives but also has an intrinsic association to a multitude of risk factors in areas such as sexuality, violence, alcohol and other substances and road driving. According to a survey conducted by IREFREA in Coimbra, in 2014 (sample: 253 men and 184 women, aged between 16 and 43 years old) many of the night goers report that "today" there is more violence and aggression in the night life (60\%), more alcohol intoxication (70\%) and higher consumption of illegal drugs (43\%). $17.6 \%$ reported having had road accidents, $21.4 \%$ have been hurt by these and $16.9 \%$ have had problems with the police. It is also too high $\mathrm{a} \%$ of individuals who reported having had sex under the influence of alcohol (64.8\%).

Results More participation, interaction and cooperation between network members; more investment on prevention and investigation; more production and exchange of content; more accession of new "actors" and more interactivity and connectivity.

Conclusions Adopting the ecological model, approaching nightlife in a public health perspective, organising care in a multidisciplinary, multisectoral network has contributed to the promotion of more involvement of the "city" aiming the safety and wellbeing of their citizens.

\section{BALANCING DATA AND PUBLIC OPINION TO ACHIEVE BEST PRACTISE IN PRIORITY SETTING}

${ }^{1}$ Venessa Wells, ${ }^{1}$ Megan De Piazz, ${ }^{1}$ Rachel Meade, ${ }^{1}$ Marc Zen, ${ }^{2}$ Tanya Van Sittert. ${ }^{1}$ Injury Control Council of Western Australia, Australia; ${ }^{2}$ City of Melville, Australia

\subsection{6/injuryprev-2016-042156.447}

Background Best practise suggests community consensus is necessary for implementing action and change. Many health practitioners struggle to implement injury prevention initiatives that meet the needs of conflicting audiences. Decision makers are often influenced by cost-saving analysis, community members can be influenced by media propaganda and practitioners themselves are often influenced by limited resources, time and expertise.

Description of the problem In 2014, Western Australian local government authority, the City of Melville, decided to identify their injury prevention priorities, as part of their submission for Pan Pacific Safe Community Accreditation. Partnering with the Injury Control Council of WA, the City of Melville held a oneday Priority Setting workshop to gain audience consensus of the city's strategic planning as well as buy-in for the Safe Community Accreditation process.

Results (effects/changes) The strength of the workshop was the balanced presentation of data and public opinion. Data presented included statistics of injury related hospitalisation, death and crime rates. Opinion was sought from representatives of state agencies, injury experts, community groups and local residents. A fair ranking (scoring) system was applied to both the data and public opinion. These rankings were combined to finalise the injury prevention priorities for the City of Melville.

Conclusions Feedback from participants stated appreciation for the opportunity to be involved, encouraged and heard. The success of the workshop is now evident with the establishment of volunteer working groups and activities, aiming to address each of the priorities in the City of Melville. The balance of data and opinion, as created by the World Health Organisation for International Safe Communities Accreditation, is an accessible, practical and adaptable framework for public health practitioners around the world.

\section{USING HEALTH BELIEF MODEL TO EXPLAIN SPEEDING BEHAVIOUR AMONG OMANI MALE DRIVERS}

${ }^{1}$ Abdullah Al Maniri, ${ }^{2}$ Ali Al Azri, ${ }^{3}$ Ibrahim Al Harthi, ${ }^{3}$ Mohammed Al Azri, ${ }^{4}$ Marie Hasselberge, ${ }^{4}$ Lucie laflamme. ${ }^{1}$ The Research Council, Oman; ${ }^{2}$ Ministry of Health, Oman; ${ }^{3}$ Sultan Qaboos University, Oman; ${ }^{4}$ Karolinska Institute, Sweden

\subsection{6/injuryprev-2016-042156.448}

Background Speeding behaviour has been recognised as one of the most important risk factor of fatal Road Traffic Crashes (RTC) and has been consistently reported as the main cause of RTCs in Oman. The aim of this study was to identify factors associated with speeding behaviour using Health Belief Model (HBM)

Methods A total of 1286 Omani male drivers visiting Directorate of Vehicle Registration at Royal Oman Police (ROP) were randomly selected and surveyed using a validated questionnaire. The questionnaire items included questions on socio-demographic characteristics, driving behaviour, driving history and the subscales of the HBM. Multivariate logistic regression was used to examine the association between speeding behaviour and the constructs of the HBM.

Results Around $60 \%$ of the drivers reported not respecting the speeding limit on the highways of which $70 \%$ of them were always crossing the speeding limit. Around 50\% of the drivers reported an involvement in a road traffic crashes in the last three years of which $10 \%$ relate the cause of the crash to speeding. A significant association between speeding behaviour and the psychosocial characteristic of the participants (Age, driving license age, having children, monthly income, motoring and speeding offences was observed. In Multivariate logistic regrsession anlayis, speeding behaviour was significantly predicted by perceived benefits of respecting the speed limits and barriers of respecting the speed limits.

Conclusions HBM serves as a good explanatory model for speeding behaviour among Omani male drivers in Oman. The perceived benefits of speeding may be used in awareness campaigns that target change of speeding behaviour.

\section{SAFETY AND HEALTH: BUILDING INJURY PREVENTION INTO THE HEALTHCARE SYSTEM}

Larry Cohen, Rachel Davis. Prevention Institute, CA, USA

\subsection{6/injuryprev-2016-042156.449}

Background (issue/problem) Beyond the direct deleterious toll on individuals, injury incurs high costs to the healthcare sector and increases the risk of other poor health outcomes, such as chronic illness and poor mental wellbeing. The healthcare sector can play 
important roles in injury prevention, not only by treating injured patients, but also by addressing the community conditions that increase the risk for injury. In order to build injury prevention into the healthcare system, healthcare organisations can benefit from models that bridge community prevention and health service delivery.

Objective In this session, participants will learn about Prevention Institute's Community-Centred Health Home (CCHH) model to promote systems change and active involvement in community advocacy. The vision of a community-centred health home takes models such as community oriented primary care and the medical home a step further by encouraging health care institutions to take an active role in strengthening their surrounding community. Results When a Chinatown resident was struck and killed by a car while crossing the street in Oakland, California, Asian Health Services (AHS) staff became aware of pedestrian safety as a health issue in their community. AHS engaged in the CCHH steps of inquiry, analysis, and action and collaborated with several community groups, business owners, and city planning agencies to instal a "scramble" crosswalk to stop vehicle traffic and allow pedestrians to safely cross in all directions. Early data showed the "scramble" reduced car-pedestrian incidents by as much as fifty percent. A larger community transportation and planning project also emerged out of the coalition to further address environmental factors impacting pedestrian safety.

Conclusions The CCHH model is being piloted in several states in the United States. The model can be applied in other counties to advance the integration of injury prevention into the healthcare system.

\section{PROFILE OF SELF-INFLICTED HARM IN LOS ANGELES BY RACE/ETHNICITY, 2001-2010}

${ }^{1} \mathrm{~S}$ Bazargan-Hejazi, ${ }^{2} \mathrm{~A}$ Ahmadi, ${ }^{3}$ Elham Rahmani, ${ }^{1} \mathrm{M}$ Mojtahedzadeh, ${ }^{1} \mathrm{D}$ Pan. ${ }^{1}$ Charles $R$. Drew University; ${ }^{2}$ Kermanshah University of Medical Sciences and Karolinska Institute; ${ }^{3}$ Boston University

\subsection{6/injuryprev-2016-042156.450}

Background Self-Inflicted Harm is one of the major causes of morbidity and mortality. Previous studies have shown that there are different patterns of SIH among different racial groups. This study aims to describe SIH admission rates and patterns among different racial groups in Los Angeles and to evaluate whether admission rates have changed over a ten year period (20012010).

Methods Data for this retrospective study includes all cases of hospital admission in Los Angeles with SIH based on the ICD-9: E950-E958 for 2001-2010. ICD-9 codes for schizophrenia, episodic mood disorders, depressive, anxiety, personality adjustment, sexual and gender identity disorders, as well as alcoholism and substance abuses were used.

Results A total of 2459 patients with SIH were identified. African Americans(AA) had the highest ten year average of SIH rate $(11.6 / 100,000)$ followed by Caucasians(CC) $(8.44 / 100,000)$, Latinos(LT) (6.21/100,000) and Asians(AS) (1.64/100,000). The SIH admission rates remained steady throughout the 10 year study period $(\mathrm{P}$ value $=0.3064)$ and none of the racial groups showed a significant change $(\mathrm{P}$ value $\mathrm{CC}=0.2445, \mathrm{AA}=0.2120$, $\mathrm{LT}=0.6898, \mathrm{AS}=0.1237)$. Median age of SIH was significantly lower in Latinos $(\mathrm{LT}=28$ versus $\mathrm{CC}=43, \mathrm{AA}=39$ and $\mathrm{AS}=$ 40 ( $\mathrm{P}$ value $<0.001)$. Overall, episodic mood disorders where the most common psychiatric comorbidity among all racial groups. However, AAs had the lowest probability of episodic mood disorder comorbidity $(\mathrm{CC}=55.87 \%$, $\mathrm{AA}=39.52 \%$, $\mathrm{LT}=41.84 \%$, AS $=47.66 \%, \mathrm{P}$ value $<0.001)$ and the highest probability of schizophrenia comorbidity $(\mathrm{CC}=10.47 \%$, $\mathrm{AA}=20.84 \%, \mathrm{LT}=8.00 \%, \mathrm{AS}=10.49 \%$, P value $<0.001)$.

Conclusions SIH admission rates as well as the gap between different racial groups have remained steady during the study period which can raise concerns about the effectiveness of programs aimed at decreasing $\mathrm{SIH}$ admission rates and/or reducing interracial disparity.

\section{Posters Monday 19.9.2016 Child and Adolescent Safety}

\section{Post Mon 1.7}

\section{INJURY INCIDENCE OF CHILDREN BELOW 5 YEARS OF AGE, IN A COMMUNITY HEALTH DIVISION IN SRI LANKA}

${ }^{1}$ Indrakantha Welgama, ${ }^{2}$ Piyanga Chandradasa, ${ }^{3}$ Samath Dharmaratne. 'Office of the Regional Director of Health Services, Colombo, Sri Lanka; ${ }^{2}$ Office of the Medical Officer of Health, Homagama, Sri Lanka; ${ }^{3}$ Department of Community Medicine, Faculty of Medicine, University of Peradeniya, Sri Lanka

\subsection{6/injuryprev-2016-042156.451}

Background Main objective of this study was to find the incidence and characteristics of injuries within the past 1 year period, suffered by children under 5 years of age in this selected community health division in Sri Lanka.

Methods This was a community based descriptive, cross sectional study covering a randomly selected area of the Homagama Community Health division in Colombo District. The population was children under 5 years who were permanent residents of that area, and a single child under the age of 5 years was randomly selected from each eligible family, following community household visits. A structured, pre-tested, interviewer administered questionnaire with trained interviewers and pictorial support material, was used for data collection, over 3 months period in 2013.

Results Of 2136 respondents, 552 (25.84\%) had a history of injury during the past 1 year. Of the 1077 (50.42\%) males, $26.92 \%$ have had injuries, while $24.74 \%$ of females too had injuries. Children aged 3 to 4 years were mainly vulnerable for injuries, while $35.3 \%$ of children have reported only one significant (as perceived by parents/guardians) injury during the past year. Common injury types were abrasions (45.82\%), lacerations $(17.06 \%)$ and contusions (9.7\%). Of those reporting injuries, $4.35 \%$ had suffered fractures. Most of the causes for these injuries were falls $(75.5 \%)$, followed by falling objects, animal attacks and burns. $67.5 \%$ of injuries had occurred at home while $17.4 \%$ had occurred in the home garden.

Conclusions From the findings of this study, it could be concluded that the incidence of injuries amongst under 5 year old children in the community in this area was $25.84 \%$ and also that the incidence was similar between both sexes. The commonest injuries were abrasions and lacerations while falls, falling objects, animal attacks and burns were the main causes of these injuries. Home and home garden were the common environments in which these injuries had occurred. 